\title{
Experiments with sediment replenishment in a residual flow reach: Comparison of field data with laboratory experiments
}

\author{
Severin Stähly ${ }^{1, *}$, Anthony Maître ${ }^{1}$, Mário J. Franca $^{1,2}$, Christopher T. Robinson ${ }^{3}$, \\ and Anton J. Schleiss ${ }^{1}$ \\ ${ }^{1}$ Laboratory of Hydraulic Constructions (LCH), Swiss Federal Institute of Technology Lausanne \\ (EPFL), Switzerland \\ ${ }^{2}$ River Basin Development Chair Group, IHE - Delft Institute for Water Education, Netherlands \\ ${ }^{3}$ Aquatic Ecology Department, Swiss Federal Institute of Aquatic Science and Technology (EAWAG), \\ Switzerland
}

\begin{abstract}
Hydropower is an important pillar of the electricity production in Switzerland and its extension is planned in the next decades. Therefore, a more sustainable management of hydropower plants is needed. Sediment replenishment combined with artificially-triggered flood pulses are gaining increasing interest to restore residual flow reaches. In the Sarine river in Switzerland, such a measure was conducted. Mimicking laboratory experiments for the first time, four deposits, totaling $1000 \mathrm{~m}^{3}$ of sediment, were added to the river downstream of Rossens dam. Some 489 pebbles were equipped with RFID PIT tags and distributed among them. After the flood pulse passed, $57 \%$ of the tags were re-located. The maximum detected travel distance of a pebble was $284 \mathrm{~m}$. Some deposits were eroded, while others resisted. Due to a limited submergence, mainly lateral erosion was observed. Nevertheless, erosion of deposits as well as deposition of eroded material in clusters resulted in the same scheme as observed in laboratory experiments which could be validated with this field experiment.
\end{abstract}

\section{Introduction}

Countries in the Alps produce much electricity through hydropower. In Switzerland, about half of the electricity produced by hydropower comes from storage hydropower plants. Some 217 large dams with heights up to $285 \mathrm{~m}$ are in operation to deliver this electricity. After decades of production, some sediment deficits in the rivers, both downstream and upstream of dams, became evident. The sediment continuum in rivers is interrupted by dams creating large reservoirs. On the one hand, reservoir sedimentation reduces the storage volume in reservoirs, whereas on the other hand, sediment deficits occur in downstream reaches. This deficit may lead to incision of the river and, in the midterm, to a disconnection between the active river bed and its riparian corridor [1]. This effect is even more profound due to hydrology, which is altered by a dam. The riparian area in a residual flow reach rarely

*Corresponding author: severin.staehly@epfl.ch 
experiences flooding [2]. With time, vegetation spreads, gravel bars disappear and dynamic habitats that are valuable for biodiversity decline, and in extreme cases even disappear. Therefore, authorities, engineers and environmentalists look for solutions. The Swiss parliament passed in 2011 a new water act law that addresses sediment restoration, hydropeaking, residual flow and fish passage restoration. An option for restoring sediment dynamics, which has been applied in the USA and Japan for decades, and has become more and more popular in Europe, is sediment replenishment $[3,4,5]$. Here, sediment is added upstream of a reach lacking sediment, often using trucks, diggers and wheel loaders. In residual-flow rivers downstream of dams, this is combined with artificially-triggered flood pulses. Flood pulses also help against colmation and restore the hyporheic zone in the river bed. Combined with sediment replenishment, habitats that favour fish spawning are created. Such a restoration measure was tested in the Sarine river downstream of Rossens dam in the canton Fribourg, Switzerland. In 1948, Rossens dam was built and the Sarine was changed drastically (see Fig. 1). Today, a constant discharge of $2.5 \mathrm{~m}^{3} / \mathrm{s}$ in winter and $3.5 \mathrm{~m}^{3} / \mathrm{s}$ in summer is released at the dam as a residual flow, creating a channel of 20 to $30 \mathrm{~m}$ width.
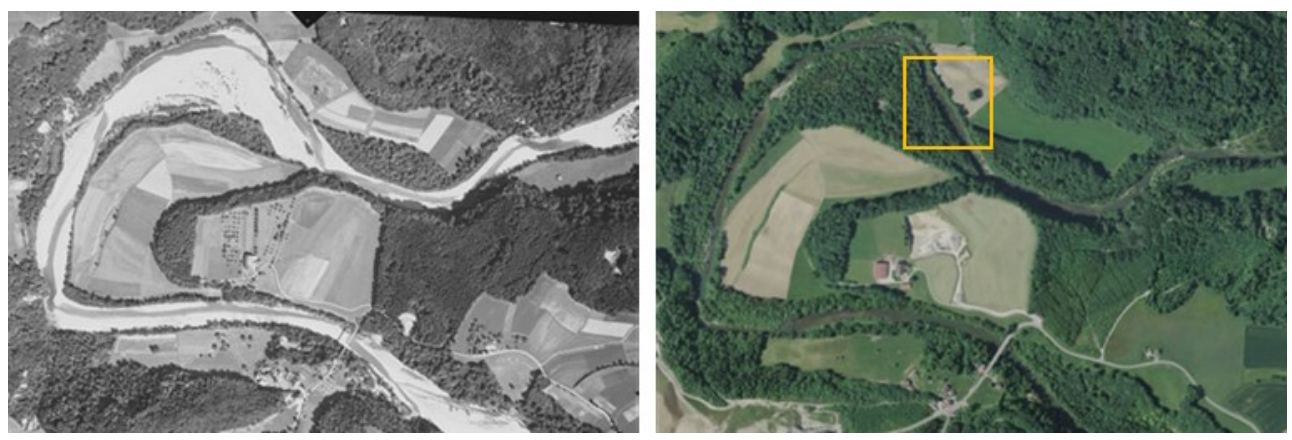

Fig. 1. Comparison of a meander at the Sarine residual flow section from 1943 (left) and 2012 (right). The active floodplain from 1943 almost disappeared. Nowadays, hardwood forest is present and the dynamic behavior of the river is strongly reduced. The yellow square corresponds to the location where the sediment replenishment was added (Fig. 2).

A field experiment of sediment replenishment combined with an artificial-triggered flood pulse was conducted in the Sarine river in September 2016. Its principle aim was to clean the river from algae and break the sediment armour layer. We used this relatively rare event to test and validate laboratory findings in large scale.

\section{Experimental setup}

\subsection{Configuration of deposits}

Laboratory experiments pointed out that for steep rivers with a longitudinal slope of $1.5 \%$, a combination of four deposits assembled as alternate bars result in a favorable deposition process $[6,7]$. Such a cluster formation in the river creates habitats that are valuable for fishes. Especially in bedrock-alluvial rivers such as the Sarine with exposed molasse rock, a deposition in clusters is more valuable for in-stream organisms than a homogenous uniform distribution in the river. As can be seen in Figure 2, deposit I and III are located touching the left bank, at a distance corresponding to one deposit length $L$. Attached to the right bank, deposit II and IV have been arranged longitudinally shifted by half a deposit length (Fig. 2). The extent of Figure 2 corresponds to the yellow square in Figure 1. Unlike in the laboratory 
experiments, which were performed in a straight trapezoidal channel with a fixed bed, the deposits were installed downstream of a bend in the river. This location was the only relatively straight reach in the strongly meandering Sarine with possible access for the digging machines.

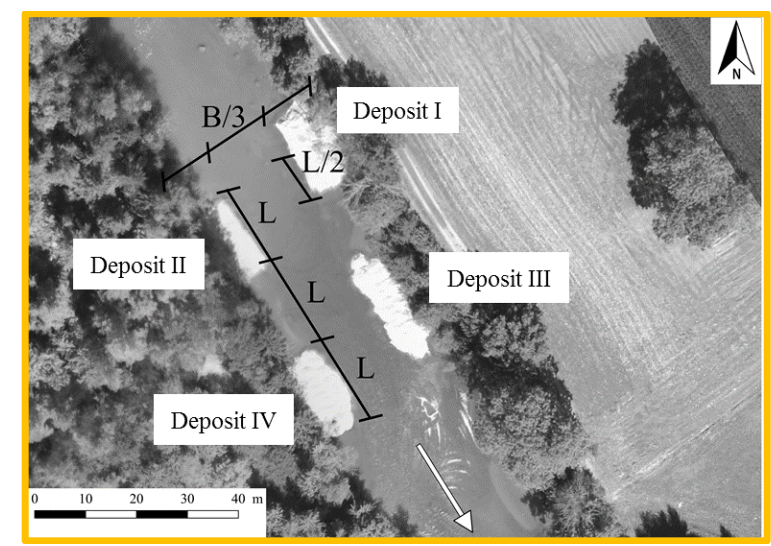

Fig. 2. The four deposits of sediment replenishment in the Sarine river. The distance between deposit I and deposit III as well as between deposit II and deposit IV was one deposit length $L$. Deposit I and deposit II are shifted by half a deposit length $L / 2$. The deposits should occupy two thirds of the river width $B$. A larger overview of this reach can be seen in Figure 1 .

\subsection{Pebble tagging}

Each deposit consisted of about $250 \mathrm{~m}^{3}$ of sediments (in total $1000 \mathrm{~m}^{3}$ of sediment) with a $d_{m}$ equal to $5.7 \mathrm{~cm}$ and $d_{90}$ equal to $11.3 \mathrm{~cm}$. The grain sizes distribution was detected with 21 analysis of line-sampling after Fehr [8] and photo-sieving using BASEGRAIN [9, 10]. The sediment in the deposits was excavated material from the floodplain on the orographic right side of the river. It was not sorted or washed before entering the river. Fine sediments were washed away by a large extent during installation. In order to track the sediment, 489 pebbles were drilled and equipped with RFID PIT tags (Radio Frequency Identification, Passive Integrated Transponder) of $2.3 \mathrm{~mm}\left(d_{m}\right)$ and $3.2 \mathrm{~mm}\left(d_{90}\right)$ lengths. The tagged pebbles then were equally placed in the four deposits at three layers: on the surface, in the middle and in the bottom of each deposit. After the tags are transported, they can be searched with a mobile antenna and the settling location of each RFID PIT tag can be noticed.

\subsection{Artificially triggered flood}

In September 2016, an artificially-triggered flood was released from Rossens dam with a peak discharge of $195 \mathrm{~m}^{3} / \mathrm{s}$ during two hours (Fig. 3). The steps on the rising limb of the hydrograph served as a calibration for gauging stations and to validate the critical discharge for sediment transport. Initially, a larger flood with a peak discharge of $255 \mathrm{~m}^{3} / \mathrm{s}$ was planned, but due to an error in the rating curves of spillway gates at Rossens dam, only a maximum discharge of $195 \mathrm{~m}^{3} / \mathrm{s}$ was reached. Thus, resulting in a significantly less powerful flood than expected. As mentioned, the hydrograph was designed by engineers to clean the river from algae and mobilize the armor layer of sediment, it was not designed after the laboratory experiments. $255 \mathrm{~m}^{3} / \mathrm{s}$ was the limit for the peak discharge, because a higher discharge may have flooded a landfill site. Therefore, the discharge was designed to stay above the threshold for particle movement for a longer time than it is the case in a natural flood with the same 
peak discharge. The critical discharge for movement of the equipped pebbles was expected to be around $100 \mathrm{~m}^{3} / \mathrm{s}$ at the location of the deposits, which had been exceeded for 9 hours. The height of the deposits were designed in a way to be completely overtopped at the initial planned discharge of $255 \mathrm{~m}^{3} / \mathrm{s}$.

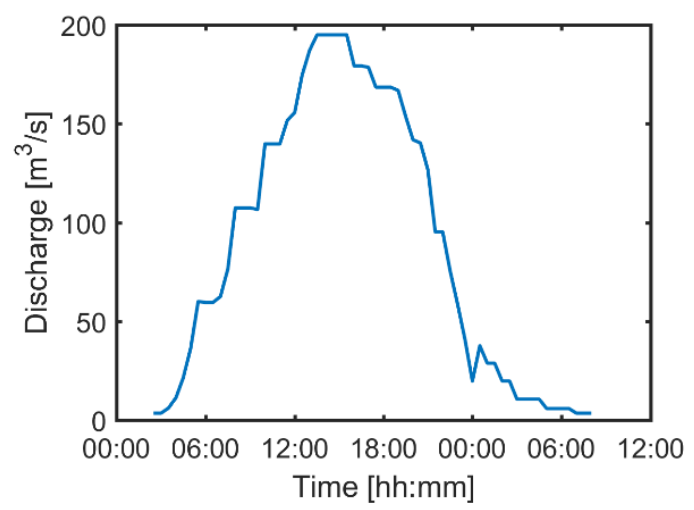

Fig. 3. The hydrograph of the artificially-triggered flood in September 2016. The peak discharge of 195 $\mathrm{m}^{3} / \mathrm{s}$ was released during two hours. The steps in the increasing limb of the hydrograph were operated with intention to calibrate gauging stations and to detect the critical discharge for sediment movement.

\section{Results}

\subsection{Deposits}

The deposits in the Sarine were only partially eroded. Deposit I and deposit IV were about half eroded, deposit II was very little eroded and deposit III only a small portion was left. In Figure 4, the outline of the deposits after the event are displayed on an air image from before the flood event. The evolution of deposit I towards the upstream indicates deposition from upstream sediment.

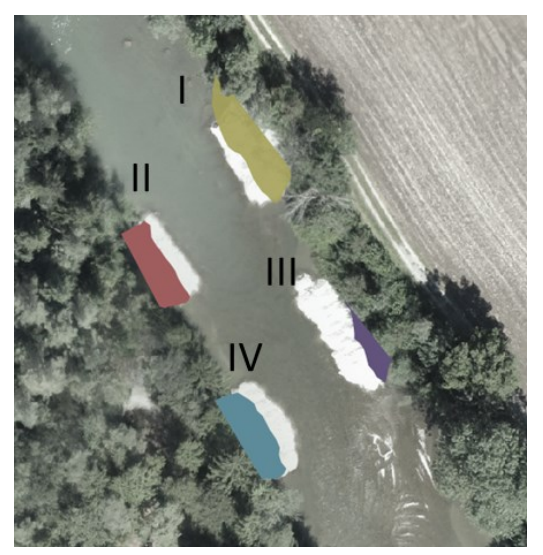

Fig. 4. The four deposits before (background image) and after (colored areas) the flood event. Deposit I and IV were half eroded, deposit II changed only a little and deposit III was mainly transported away. 


\subsection{RFID PIT tags}

From the RFID PIT tags, 277 were redetected after the flood event, equalling $57 \%$ of the 489 put into the river. Since a large part of the deposits were not eroded, many of them were detected on the deposits. Some 166 pebbles were detected in the river and used for the following analysis. The pebbles from deposit I travelled the farthest at $286 \mathrm{~m}$, followed by the pebbles from deposit III and IV at $244 \mathrm{~m}$, and $181 \mathrm{~m}$ from deposit II (Table 1). Figure 5 points out that the tags from deposit I and III were in average further transported than from the other deposits, but the location in the deposit (top, middle bottom) did not have a significant influence on the transported distance.

Table 1. Statistics of the 166 detected RFID PIT tags in the river. The first part gives information about where the tags were put in the deposits before the flood, either on top of the deposit, in the middle, or in the bottom. The lowest rows give information about the distance they travelled.

\begin{tabular}{|lc|c|c|c|c|}
\hline Deposit & & I & II & III & IV \\
\hline Tags from top & {$[-]$} & 15 & 12 & 25 & 23 \\
Tags from middle & {$[-]$} & 17 & 10 & 28 & 9 \\
Tags from bottom & {$[-]$} & 10 & 5 & 12 & 0 \\
Total tag \# & {$[-]$} & 42 & 27 & 65 & 32 \\
d90 & {$[-]$} & 20 & 18 & 37 & 25 \\
d & {$[-]$} & 22 & 9 & 28 & 7 \\
Max d90 & {$[\mathrm{m}]$} & 278 & 181 & 242 & 244 \\
Avearge d90 & {$[\mathrm{m}]$} & 93 & 20 & 87 & 44 \\
Max $\mathrm{d}_{\mathrm{m}}$ & {$[\mathrm{m}]$} & 286 & 108 & 244 & 68 \\
Average $\mathrm{d}_{\mathrm{m}}$ & {$[\mathrm{m}]$} & 139 & 33 & 109 & 29 \\
\hline
\end{tabular}



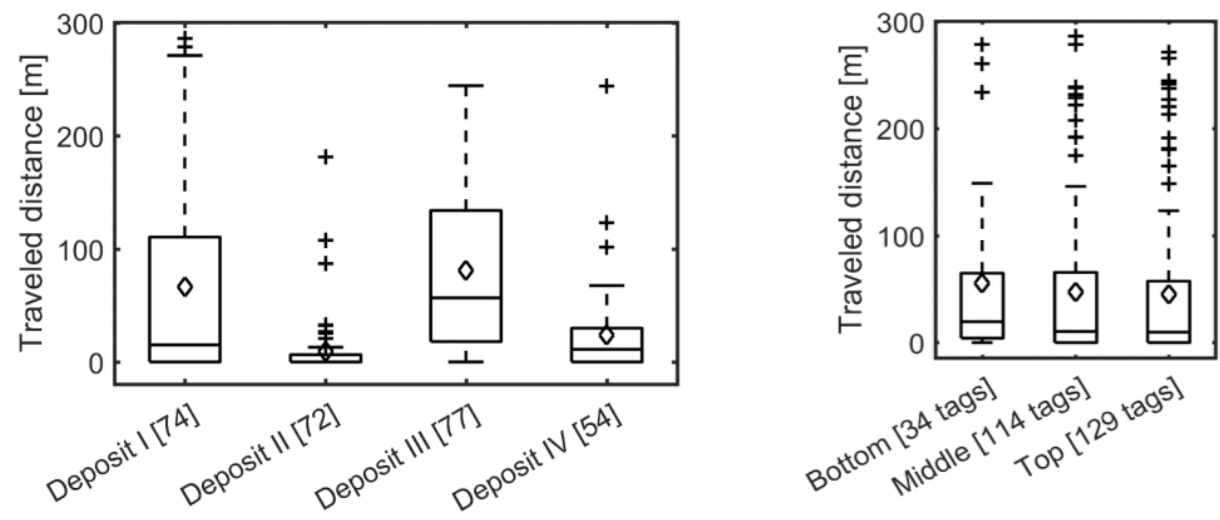

Fig. 5. Transport distances of the RFID PIT tag equipped stones in the Sarine river. The left figure corresponds to the deposit of origin, the right figure to the location in the deposit.

The distribution of the tagged pebbles in the river revealed clusters. A first deposition cluster can be observed at a distance of about one river width downstream of deposit IV. There, especially pebbles from deposit I and IV were found. Another river width further downstream, a second deposition cluster is present. There, mainly cobbles from deposit I and III were found. Transversal dispersion of the pebbles, meaning that pebbles from a deposit from the left river bank were found in the right part of the river and vice-verse, was not observed. After this second cluster, there were some single pebbles but not a cluster until the pool. Downstream of the pool, another sediment deposition cluster can be detected with mainly pebbles from deposit III and I. One single pebble of deposit IV was also found. As already calculated in Table I, Figure 6 shows that the pebbles from deposit I and III travelled on average further than pebbles from deposit II and IV.

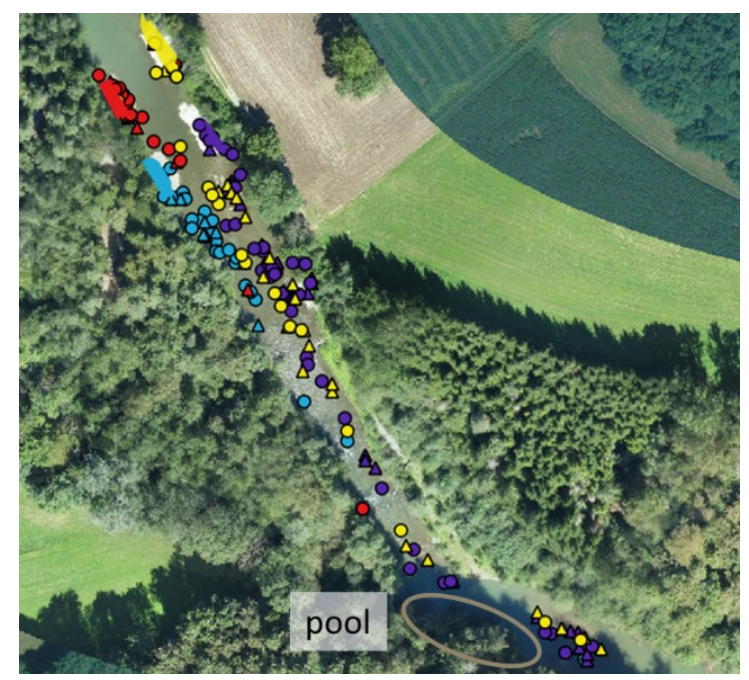

Fig. 6. Distribution of the RFID PIT tag equipped stones in the Sarine river. The color indicates the origin of the stones from the initial deposit. There is a pool in the bend downstream. $D 90$ are indicated with a circle, $d_{m}$ with a triangle. 


\section{Discussion}

In total, $57 \%$ of the PIT tag-equipped pebbles were detected. There are multiple possibilities where the remaining $43 \%$ could be. First of all, a transponder may emit a weaker signal than a neighbouring transponder and therefore the antenna only detects the stronger signal. This may be due to the orientation of the tag or its size [11]. A second reason is that some of the equipped pebbles are still in the bottom of the deposits or covered by a large layer of other sediments. The detection distance of the antenna varies between 30 and $60 \mathrm{~cm}$. Is the equipped pebble is covered by a thicker layer, it cannot be detected. The third reason is that the pebbles are in the deep pool and could not be accessed with the antenna (Fig. 6). A fourth and last reason is that pebbles were transported further than the reach in which we searched. After the last tagged pebble was detected, another $100 \mathrm{~m}$ of river were searched with the antenna, without finding anything. However, the fact that multiple tagged $d_{m}$ and $d_{90}$ from the top layer in deposit III are missing, leads to the thought that they might be further transported in the river than the recorded $284 \mathrm{~m}$.

As mentioned, the artificial flood in the Sarine river did not fully erode the deposits. With the low peak discharge, the submergence of the deposits was minimal and mainly lateral erosion took place. This fact is supported by Figure 5 indicating that tagged stones installed in the top, middle and bottom move the same distance. With the initially planned discharge, the submergence of the deposits would have been significantly higher. Thus, the shear stress on the top layer would have been larger and the stones from the top layer would have been further transported in average than the stones from the bottom layer.

In the current case, the results need to be compared with an intermediate state of the laboratory results (see Fig. 7, [6]). The results from time step $t=60 \mathrm{~min}$ corresponds with the observation from in the Sarine. Deposit III is almost fully eroded, deposit I almost untouched, deposit II and IV show an erosion pattern that is also observed in Figure 6. The difference in deposit I may come from the fact that the replenishment is located just downstream of a mild river bend (Fig. 1) that induces secondary currents, and the stress on deposit I is higher than in a straight channel. Concerning the deposition of the replenishment, there is one large cluster forming in the channel in a distance corresponding to three channel widths downstream of deposit IV. This can also be observed in the field experiment, in a distance one and two river widths downstream of deposit IV. Analysing the morphology in the Sarine, these two clusters are located upstream of a relatively long riffle. In this riffle, large boulders are present and smaller pebbles either pass this reach or settle in front of it. A few of the equipped pebbles got stuck in these large boulders, as seen in Figure 6.

$$
\mathrm{t}=30 \mathrm{~min}:
$$

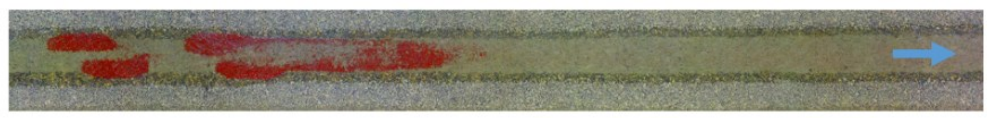

$\mathrm{t}=60 \mathrm{~min}:$

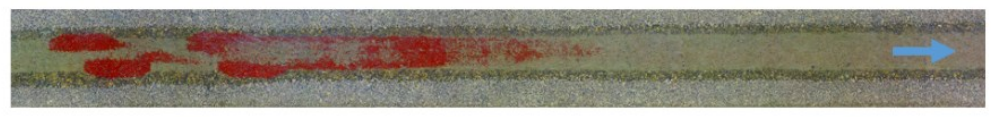

$$
\mathrm{t}=120 \mathrm{~min}
$$

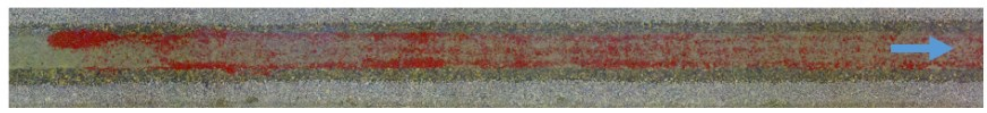

Fig. 7. Laboratory experiment with replenishment in a trapezoidal channel. The situation after the flood event in the Sarine corresponds mainly to the state after $t=60 \mathrm{~min}$ [6]. 


\section{Conclusion}

Despite the flood not having the intended hydrograph and consequently the influence as planned, the results correspond to an intermediate state of the laboratory experiments where only lateral erosion was present, and submergence of the deposits was minimal. In both situations, erosion was highest in deposit III and lead to cluster formation downstream. Due to the relatively small effect of the flood, a high percentage of PIT tags could be detected and analysed. Further observations at the Sarine with future floods will give more information about the validation of the laboratory experiments in the field.

\section{Acknowledgement}

Diego Tonolla, Kevin Gianom and Jonas Durand-Gasselin helped in the preparation and the measurements during the artificial flood. Elena Battisacco conducted the laboratory experiments. This research project is part of the National Research Programme "Energy Turnaround" (NRP 70) of the Swiss National Science Foundation (SNSF). Further information on the National Research Programme can be found at www.nrp70.ch. Further financial support was received by the cantonal authorities of Fribourg, Switzerland.

\section{References}

1. F.K. Ligon, W.E. Dietrich, W.J. Trush, BioScience, 45(3), 183-192 (1995)

2. G.E. Petts, A.M. Gurnell, Geomorphology, 70(1-2), 27-47 (2005)

3. G.M. Kondolf, Env. Management, 21(4), 533-551 (1991)

4. S.A. Brandt, Int. J. of Water Res. Dev., 16(3), 343-367 (2000)

5. G. Ock, T. Sumi, Y. Takemon, Hydrological Research Letters, 7(3), 54-59 (2013)

6. E. Battisacco, EPFL Thesis No. 7239 and LCH Communication 67, Ed. A. Schleiss, Lausanne, pp. 241 (2016)

7. E. Battisacco, M.J. Franca, A.J. Schleiss, Water Resources Research, 52(11), 8879-8894 (2016)

8. R. Fehr, Schweizer Ingenieur und Architekt, 38, 1104-1109 (1987)

9. M. Detert, V. Weitbrecht, In River Flow. Tylor \& Francis Group London, 595-600 (2012)

10. S. Stähly, H. Friedrich, M. Detert, Journal of Hydraulic Engineering, 143(6), 06017005 (2017)

11. F. Arnaud, H. Piégay,L. Vaudor,L. Bultingaire, G. Fantino, Geomorphology, 238, 3746, (2015) 